\title{
RELATIONSHIP AMONG MATERNAL, PRENATAL AND PREGNANCY OUTCOME IN RANGELI MUNICIPALITY OF NEPAL
}

\author{
Asmita Mahato $1,{ }^{*}{ }^{2} \otimes(i D)$, Barsha Shrestha 3 不 \\ ${ }^{1}$ AASRA Research and Education Academy Counsel, Janpriya Tole, Biratnagar-6, Nepal \\ ${ }^{* 2}$ Department of Military and Veterans Affairs, New Jersey Veterans Memorial Home, NJ, USA \\ ${ }^{3}$ Rangeli Hospital, Rangeli Municipality, Morang, Nepal
}

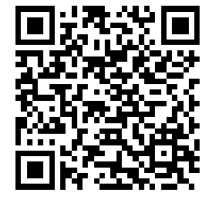

DOI: https://doi.org/10.29121/granthaalayah.v8.i11.2020.2279

Article Type: Research Article

Article Citation: Asmita Mahato, and Barsha Shrestha. (2020).

RELATIONSHIP AMONG MATERNAL, PRENATAL AND

PREGNANCY OUTCOME IN

RANGELI MUNICIPALITY OF NEPAL. International Journal of Research GRANTHAALAYAH, 8(11), 237-244. https://doi.org/10.29121/granthaa layah.v8.i11.2020.2279

Received Date: 01 October 2020

Accepted Date: 30 November 2020

Keywords:

Advanced Maternal Age

Cesarean Delivery

Obstetric Outcomes

\section{ABSTRACT}

Background: The incidence of pregnancy complications may be due to risk factors during pregnancy. Whether maternal parameters like age, gravida/ parity, gestational age, and fetal heart rate have any influence to the delivery outcome and newborn weight is a big quest. A young age at birth is more common in Nepal and carries a less social stigma, and hence enforces this study to understand the impact.

Objective and methodology: The objectives of this retrospective study were to evaluate the maternal and prenatal outcomes of pregnancies and the effects of the age of the pregnancy, gravida, gestational age, and newborn weight. Pregnant women giving birth in Rangeli Hospital, Morang (Nepal) in 2019 were retrospectively screened. Pregnant women of all age group were included in this study.

Results: Mean maternal age for delivery of child was $22.45 \pm 0.225$ years. $41.9 \%$ of study subjects were primigravida (G1), while $58.1 \%$ were multi-gravida (G2-4). The mean age of primigravida is $20.57 \pm 0.025$ years. Mean gestational week, fetal heart rate (FHR), and newborn weight were $38.18 \pm 0.11,140.91 \pm 0.43$, and $2870.65 \pm 26.13$ g respectively. Almost onethird (32.1\%) of the newborn were preterm babies. $20.9 \%$ of the newborn child was low birth weight. Spontaneous vaginal delivery was seen in $90.7 \%$ of the pregnancy while $7.9 \%$ had caesarean section.

Conclusion: A significant positive correlation was seen of age with gravida, parity, and newborn weight. Newborn weight was significantly related to gestational age. There is no significant difference between the mean maternal age of mother delivering preterm baby or term-baby. No significant difference in the mean age of the mother or the mean gestational duration between male and female children could be established. Significant mean differences were seen in the maternal age of LBW child and normal birth weight child.

\section{INTRODUCTION}

A baby born with less than 2500 grams is termed as Low birth weight (LBW) baby which is a major cause of child morbidity and mortality [1]. The increased risks of LBW among offspring of adolescent mothers (generally defined as women having age less than 20 years) are evident through several studies[2],[3]. It is very common in

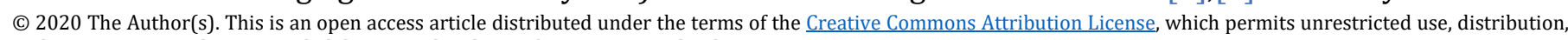
and reproduction in any medium, provided the original author and source are credited. 
low-income countries[4]. A recent study conducted in Nepal using the Nepal Demographic and Health Survey 2011 data presented that the prevalence of LBW was 15.4\% [5]. On the contrary, both high-income countries (HIC) and middle-income countries (MIC) have a concern about adverse perinatal outcomes towards older mothers [6]. It has been suggested that adolescent mothers are still developing and growing, and hence, mother and offspring may compete for the supply of nutrients[7].

Advanced maternal age (AMA) is defined as the mother being aged 35 years or above at the time of birth[8],[10]. Comparing normal birth weight children to LBW children, LBW children have more respiratory, cognitive, and neurological problems. Similarly, preterm babies have higher risks of lung disorders, heart defects, cerebral palsy, and delayed development[11].

Gravida is the total number of maternal pregnancies which includes normal and abnormal intrauterine pregnancy, abortion, ectopic pregnancy and hydatidiform mole[12],[13]. Parity can be defined as the number of births experienced by the mother. As per the study, the safest parity is 2-3 children [14]. Primigravida and gravida $\geq 4$ is also one of the factors in the emergence of problems in pregnancy and childbirth[15]. Although few studies propose differences in fetal heart rate (FHR) patterns between male and female fetuses, the baseline FHR between male and female fetuses is not significantly different[16].

Since a young age at birth is more common in Nepal and carries a less social stigma, this study has focused on the analysis of the finding of pregnancy age and birth weight of offspring.

\section{METHODOLOGY}

This study was a retrospective descriptive quantitative approach. The data was taken from July 2019 to February 2020. Rangeli Hospital is located in Rangeli municipality of Eastern Nepal which is also a birth centre established by the Government of Nepal. This study was approved by the Medical Supervisor of the Rangeli Hospital of Government of Nepal.

\subsection{DATA}

Our study used data from the Rangeli Hospital (Nepal) birth registers. Data of 244 pregnant women with the delivery record was analyzed. This study was limited to singleton births, whether live or stillborn. Multiple deliveries were not found and so there was no concern of being a higher-risk group for LBW. Birthweight was dichotomized as LBW and Normal Birth Weight. Four dependent variables were used in this study: whether the child was born with LBW (less than 2,500 g at birth); whether the child was delivered preterm (at less than 37 weeks of gestation); whether the maternal age was below 20 years of age, and whether the parity was nulliparous or multiparous. The obstetrical history of a mother like the number of previous miscarriages and whether she had any previous stillbirths were taken. Maternal' s age, gravida, parity, week of gestation, FHR, newborn weight, and delivery type were the variables taken into the study.

\subsection{MATERNAL AGE AT BIRTH}

The key explanatory variable was maternal age at the birth of the child, which was also extracted from the birth register. Maternal age data was divided into the following categories, in years: $<19,20-24,25-29,30-34$. Out of 244 pregnant women data, data of 215 pregnant women were used in the study as it had a complete set of information needed for the study. During eight months of study, no case of age group $<18$ years was reported, while only one patient 35 years of age with gravida 4 and 38 weeks of gestation was recorded. As the data was insufficient for advanced maternal age (AMA) analysis, it was excluded from the study. Out of 244 cases, six cases were of stillbirth only while one case was of stillbirth and maternal death. So, these seven cases were excluded from the study. In total, $11.9 \%[29]$ of data were excluded due to missing values.

\subsection{STATISTICAL ANALYSES}

Data from this study were analyzed using Statistical Package for the Social Sciences (SPSS) version 21.0 software. T-test, Fisher exact, Pearson's Chi-square tests, and Pearson's correlation were used for statistical analysis 
Asmita Mahato, and Barsha Shrestha

data. P-values $<0.05$ were considered statistically significant. The main association of maternal age with LBW and gestational age with birth weight was tested. The association between lower maternal age and birth outcomes were compared using two approaches. The standard approach used in this study[11] consists of analyzing the association between maternal age and the risk of LBW or preterm delivery by comparing the children born to different mothers. It was hypothesized that younger maternal ages ( $<20$ years old) are associated with increased risk for many labor and delivery complications. Fetal outcomes were also examined which may also be associated with maternal age.

\section{RESULT}

Of the total 215 maternal pregnancy, the mean maternal age for delivery of child was $22.45 \pm 0.225$ years (Table 1). Twenty-five percentile of maternal age were 20 years, 50 percentiles were of 22 years, and 75 percentiles were of 25 years age group. Of the 215 pregnant women who presented to Rangeli Hospital, 32 (14.9\%) were <20 years old, 123 (57.2\%) were 20-24 years old, 47 (21.9\%) were 25-29 years old, while $13(6 \%)$ were in the age range of 30-34 years.

Mean of gravida and parity were 1.86 and 0.86 respectively. $41.9 \%$ of the study subjects were primigravida $\left(\mathrm{G}_{1}\right)$, while $58.1 \%$ were multi-gravida $\left(\mathrm{G}_{2-4}\right) .42 .8 \%$ of the subjects were primipara followed by $\mathrm{P}_{1-2}(54 \%)$ and $\mathrm{P}_{3}(3.3 \%)$. Though maximum cases $(57.2 \%)$ of gravida (primigravida and multigravida) and parity (primipara, $\left.\mathrm{P}_{1-2}, \mathrm{P}_{3}\right)$ was found in the age group of (20-24) years with a mean gravida of 1.8 and mean parity of 0.79 ; the highest mean gravida and parity was found in 25-29 years age group. Of the primigravida, 30\% were from the age group of $<20$ years while $59.9 \%$ were from age group of 20-24 years. Mean age of primigravida is $20.57 \pm 0.025$ years (CI 20.07-21.06).

The mean of gestational week, fetal heart rate (FHR), and newborn weight were $38.18 \pm 0.11,140.91 \pm 0.43$ and $2870.65 \pm 26.13$ grams respectively. Mean gestational age (37.53 weeks) was the lowest in $<20$ years age group while it was the highest (38.42 weeks) in the age group of $20-24$. Almost one-third $(32.1 \%)$ of the baby born was preterm babies. The mean of newborn weight $(2753.7 \mathrm{~g})$ was the lowest in $<20$ years age group while it was the highest (3045.38 g) in the age group of 25-29. The weight of 45 (20.9\%) of the newborn child was below $2500 \mathrm{~g}$ while $170(79.1 \%)$ were having weight $\geq 2500$ g. Spontaneous vaginal delivery (SVD) was seen in $90.7 \%$ of the pregnancy while $7.9 \%$ had caesarean section (CS) and only $1.4 \%$ were assisted with vacuum delivery. The percentage of CS in the age group of $<20$ years was $12.5 \%$ against the age group of $>20$ years which was $7.1 \%$.

Though the study was not aimed at stillbirth and maternal death during delivery, it was found that $2.9 \%$ of the case was of stillbirth and $0.41 \%$ case of maternal death during delivery.

\subsection{STATISTICAL ANALYSIS}

A strong positive correlation (Table 2) was seen between age and gravida ( $\mathrm{r}=0.526, \mathrm{p}<0.01)$; and age and parity $(\mathrm{r}=0.527, \mathrm{p}<0.01)$. Newborn weight was positive but weakly associated with age $(\mathrm{r}=0.153, \mathrm{p}<0.05)$, gravida $(\mathrm{r}=0.14$, $\mathrm{p}<0.05)$, parity $(\mathrm{r}=0.143, \mathrm{p}<0.05)$, and gestational age $(\mathrm{r}=0.31, \mathrm{p}<0.01)$.

Independent sample T-test presented that there is no significant difference between the mean maternal age of mother delivering a preterm baby $(<37$ weeks) or term-baby ( 237 weeks). No significant difference in the mean age of the mother or the mean gestational duration between male and female children could be established (Table 3). Significant mean differences were seen in the maternal age of LBW child and normal birthweight child $(t=-2.923, p$ $<0.01$ ). The risk of having LBW infants in primiparous mothers was non-significant with multiparous mothers $(\mathrm{t}=0.526)$. The t-test also highlights that there is no difference between the fetal heart sound of the male and female child. The mean birth weight was significantly different between preterm baby and term-baby at 0.01 level of significance. This established that preterm baby weight is different from term-baby.

Using Pearson's chi-square test or Fisher's exact test, the statistical significance of newborn sex with other parameters were evaluated. The sex of the newborn babies was independent of term baby or preterm baby (Pearson's $\chi^{2}=1.752, \mathrm{df}=1, \mathrm{p}=0.186$ ). Also, the sex of newborns had no significance with LBW or normal birth weight (Pearson's $\chi^{2}=0.041, \mathrm{df}=1, \mathrm{p}=0.839$ ) as well as maternal age category (Pearson's $\chi^{2}=7.446, \mathrm{df}=3, \mathrm{p}=0.059$ ). With Fisher's exact test, newborn sex didn't show any significant relationship with week of gestation $\left(\chi^{2}=11.596\right.$, $\mathrm{p}=0.201)$, gravida $\left(\chi^{2}=3.834, \mathrm{p}=0.283\right)$, parity $\left(\chi^{2}=3.139, \mathrm{p}=0.377\right)$, newborn weight $\left(\chi^{2}=22.964, \mathrm{p}=0.79\right)$, and FHR $\left(\chi^{2}=16.538, p=0.542\right)$. Meanwhile, Fisher Exact test established that there is no association of type of delivery with maternal age, gravida, parity, week of gestation, newborn sex, and newborn weight (Table 4). 
Table 1: Descriptive Statistics of maternal pregnancy and newborn parameters of Rangeli Hospital, Morang

\begin{tabular}{|c|c|c|c|c|c|c|}
\hline & \multicolumn{6}{|c|}{ Mean \pm Std. ErrorStd. Deviation|MedianMode Minimum|Maximum } \\
\hline Age & \multirow{5}{*}{$\begin{array}{c}22.45 \pm 0.225 \\
1.86 \pm 0.059 \\
0.84 \pm 0.059 \\
38.18 \pm 0.110 \\
140.91 \pm 0.433\end{array}$} & 3.306 & 22 & 20 & 18 & 33 \\
\hline Gravida & & 0.864 & 2 & 1 & 1 & 4 \\
\hline Parity & & 0.861 & 1 & 0 & 0 & 3 \\
\hline WOG & & 1.618 & 38 & 38 & 31 & 42 \\
\hline FHS & & 6.351 & 140 & 140 & 110 & 162 \\
\hline Newborn Wei & $2870.65 \pm 26.132$ & 383.172 & 2840 & 2700 & 2000 & 4000 \\
\hline
\end{tabular}

Total number of patient $(\mathrm{N})=215$. Maternal pregnancy and newborn parameter like Age, Gravida, Parity, Week of Gestation (WOG), Fetal Heart Sound (FHS) and Newborn Weight.

Table 2: Correlation coefficient of six parameters of maternal pregnancy and newborn parameters of Rangeli Correlations ${ }^{c}$ Hospital, Morang

\begin{tabular}{|c|c|c|c|c|c|c|c|}
\hline \multicolumn{8}{|c|}{ Age|Gravida|ParityGestation FHS|Newborn Weight } \\
\hline \multirow[t]{2}{*}{ Age } & Pearson Correlation & 1 & $.526^{* *}$ & $.527^{* *}$ & .017 & .081 & $.153^{*}$ \\
\hline & Sig. (2-tailed) & & .000 & .000 & .803 & .238 & .025 \\
\hline \multirow[t]{2}{*}{ Gravida } & Pearson Correlation & & 1 & $.988^{* *}$ & .005 & .057 & $.140^{*}$ \\
\hline & Sig. (2-tailed) & & & .000 & .944 & .404 & .040 \\
\hline \multirow[t]{2}{*}{ Parity } & Pearson Correlation & & & 1 & .001 & .064 & $.143^{*}$ \\
\hline & Sig. (2-tailed) & & & & .993 & .351 & .036 \\
\hline \multirow[t]{2}{*}{ Gestation } & Pearson Correlation & & & & 1 & .040 & $.310^{*}$ \\
\hline & Sig. (2-tailed) & & & & & .561 & .000 \\
\hline \multirow[t]{2}{*}{ FHS } & Pearson Correlation & & & & & 1 & .106 \\
\hline & Sig. (2-tailed) & & & & & & .121 \\
\hline \multirow[t]{2}{*}{ Newborn Weight } & Pearson Correlation & & & & & & 1 \\
\hline & Sig. (2-tailed) & & & & & & \\
\hline
\end{tabular}

**. Correlation is significant at the 0.01 level (2-tailed).

*. Correlation is significant at the 0.05 level (2-tailed).

c. Listwise $\mathrm{N}=215$

Pearson correlation analysis (2-tailed) at significance level of 0.05 and 0.01 for maternal pregnancy and newborn parameter like Age, Gravida, Parity, Week of Gestation, Fetal Heart Sound (FHS) and Newborn Weight in order to evaluate the degree of interrelationship and association between two variables.

Table 3: T-test of several parameters of maternal and child variables

\begin{tabular}{|c|c|c|c|c|c|c|}
\hline Variables & F score & t value & $\mathrm{df}$ & $\mathrm{p}$ & \multicolumn{2}{|c|}{ Confidence interval } \\
\cline { 5 - 7 } & & & & & Lower & Upper \\
\hline Maternal age * Term of baby & 0.62 & -0.57 & 213 & 0.569 & -1.822 & 1.005 \\
\hline Maternal age * birth weight & 4.501 & -2.923 & 33.901 & 0.006 & -2.84 & -0.51 \\
\hline Maternal age * Child sex & 8.426 & 1.748 & 201.38 & 0.082 & -0.1 & 1.671 \\
\hline Week of gestation * Child sex & 1.759 & -1.131 & 213 & 0.259 & -0.684 & 0.185 \\
\hline Fetal Heart Rate * Child Sex & 0.733 & -0.601 & 213 & 0.548 & -2.232 & 1.188 \\
\hline Birth weight * Term of baby & 0.00 & -4028 & 213 & 0.000 & -481.0 & -164.903 \\
\hline Birth weight * Parity & 1.094 & 0.297 & 201.91 & 0.6 & -0.063 & 0.109 \\
\hline
\end{tabular}

$\mathrm{df}=$ Degree of freedom. $\mathrm{P}=$ level of significance.

Table 4: Fisher's Exact test $\chi^{2}$ value for selected variables of delivery type with several Maternal and Newborn Parameters

\begin{tabular}{|c|c|c|c|}
\hline & Fisher's Exact test $\chi^{2}$ value & $\mathrm{p}$ value & Remarks \\
\hline Delivery type * Maternal age & 27.978 & 0.381 & Non-significant \\
\hline Delivery type * Gravida & 3.915 & 0.695 & Non-significant \\
\hline Delivery type * Parity & 4.634 & 0.575 & Non-significant \\
\hline
\end{tabular}


Asmita Mahato, and Barsha Shrestha

\begin{tabular}{|c|c|c|c|}
\hline Delivery type * Week of Gestation & 21.585 & 0.342 & Non-significant \\
\hline Delivery type * Newborn Sex & 3.479 & 0.156 & Non-significant \\
\hline Delivery type * Newborn weight & 7.691 & 0.179 & Non-significant \\
\hline
\end{tabular}

$\mathrm{P}=$ level of significance.

\section{DISCUSSION}

In this present study, the mean maternal age for delivery of the child (22.45 years) was similar to the study (22.85 years) in West Bengal, India [17]. 14.9\% and 85.1\% were aged below 20 years and 20-34 years respectively which was similar to the findings in Bhaktapur, Nepal [18]. The overall mean of birth weight (2870.65 $\pm 26.13 \mathrm{~g})$ was higher than the findings $(2742.56 \pm 507.84 \mathrm{~g})$ of Apte et al in India[19]. The prevalence of low birth weight (20.9\%) in this study was slightly lower in other studies [17],[20],[21]. Kayastha and Tuladhar of Nepal [22] reported only $11.9 \%$ of LBW. The female and male children had no association with birth weight which was against the study of Apte et al [19],[23] showing females association with lower birth weights. About one-third (32.1\%) were preterm baby which was supported by findings of Kumar et al [17] in West Bengal, India.

The prevalence of primigravida (41.9\%) and multi-gravida (58.1\%) in this study were in agreement with the findings of Pokhara, Nepal by Timilsina et al[24]. The mean gestational week of this study was $38.18 \pm 0.11$ which was lower than the findings in Surinam (39.0 weeks) by de Wilde et al [25]. The mean of fetal heart rate (FHR) 140.91 \pm 0.43 was higher than the findings of Pildner von Steinburg et al [26], but the value is within the acceptable range of 110 to 150 or 160 beats per minute (bpm) [27],[28]. Other studies also showed that there is no significant difference in the mean fetal heart rate of male and female children[29],[30].

Only 7.9\% of newborn was delivered by caesarean section which was lower than the findings of Gogoi in Assam, India[21]. This study showed that there is no significant association of type of delivery with maternal age, gravida, parity, week of gestation, newborn sex, and newborn weight which was aligned with the findings of Gogoi in Assam, India[21] except with birth weight.

Newborn weight was positively associated with age, gravida, parity, and gestational age with $\mathrm{p}<0.05$ which was following several other studies [31]. Mean birth weight, mean maternal age, and gestational age demonstrated no significant difference between male and female child which was in concurrence with other studies [30],[32],[33]. In this study, no significant difference in the mean maternal age of mother delivering a preterm baby or term-baby was observed which was against the findings of Fuchs et al [30],[34]. The risk of having LBW infants in primiparous mothers was non-significant with multiparous mothers in this study while Nazari et al suggested otherwise [35].

\section{CONCLUSION}

A significant positive correlation was seen of age with gravida, parity, and newborn weight. Newborn weight was significantly related to gestational age. There is no significant difference between the mean maternal age of mother delivering preterm baby or term-baby. No significant difference in the mean age of the mother or the mean gestational duration between male and female children could be established. Significant mean differences were seen in the maternal age of LBW child and normal birth weight child.

\section{LIMITATIONS}

The study only included the pregnant women visiting the hospital for delivery so the results cannot be generalized as a true image of the general population. This study didn't consider the socioeconomic status of pregnant women.

\section{LIST OF ABBREVIATIONS}

FHR: fetal heart rate; SVD: Spontaneous vaginal delivery; CS: caesarean section; LBW: Low birth weight; HIC: high-income countries; MIC: middle-income countries; g: gram; AMA: Advanced maternal age; SPSS: Statistical Package for the Social Sciences. 
Relationship Among Maternal, Prenatal and Pregnancy Outcome in Rangeli Municipality of Nepal

\section{SOURCES OF FUNDING}

No funding of any sort was received for the study.

\section{CONFLICT OF INTEREST}

The authors declare that they have no competing interests.

\section{AUTHORS' CONTRIBUTIONS}

$\mathrm{AM}$ and BS were involved in planning the research, study design, analysis, and writing the manuscript; BS was involved in data collection and compiling, preparation of the report; AM was involved in analysis, review, and editing. All authors read and approved the final manuscript.

\section{ACKNOWLEDGMENT}

We honestly appreciate the visionary efforts and inputs of AASRA Research \& Education Academy Counsel for making this study possible. We are grateful to Medical Superintendent of Rangeli Hospital, Dr. Rohendra Pande, for permission of data collection. We are also thankful to those individuals who made this study possible through their contribution by any means.

\section{REFERENCES}

[1] Tshotetsi L, Dzikiti L, Hajison P, Feresu S. Maternal factors contributing to low birth weight deliveries in Tshwane District, South Africa. PLos One. 2019;14(3): e0213058.

[2] Restrepo-Méndez MC, Lawlor DA, Horta BL, Matijasevich A, Santos IS, Menezes AM, et al. The association of maternal age with birthweight and gestational age: a cross-cohort comparison. Paediatr Perinat Epidemiol. 2015;29(1):31-40.

[3] Dennis JA, Mollborn S. Young maternal age and low birth weight risk: An exploration of racial/ethnic disparities in the birth outcomes of mothers in the United States. Soc Sci J. 2013;50(4):625-634.

[4] Acharya D, Singh JK, Kadel R, Yoo SJ, Park JH, Lee K. Maternal Factors and Utilization of the Antenatal Care Services during Pregnancy Associated with Low Birth Weight in Rural Nepal: Analyses of the Antenatal Care and Birth Weight Records of the MATRI-SUMAN Trial. Int J Environ Res Public Health. 2018;15(11):2450.

[5] Singh U, Ueranantasun A, Kuning M. Factors associated with low birth weight in Nepal using multiple imputation. BMC Pregnancy Childbirth. 2017; 17:67.

[6] Fall CH, Sachdev HS, Osmond C, Restrepo-Mendez MC, Victora C, Martorell R, et al. Association between maternal age at childbirth and child and adult outcomes in the offspring: a prospective study in five lowincome and middle-income countries (COHORTS collaboration). Lancet Glob Health. 2015;3(7):e366-e377.

[7] Wallace JM. Competition for nutrients in pregnant adolescents: consequences for maternal, conceptus and offspring endocrine systems. J Endocrinol. 2019;242: T1-19.

[8] Rubenstein E, Durkin MS, Harrington RA, Kirby RS, Schieve LA, Daniels J. Relationship Between Advanced Maternal Age and Timing of First Developmental Evaluation in Children with Autism. J Dev Behav Pediatr. 2018;39(8):601-609.

[9] Stylianou-Riga P, Kouis P, Kinni P, Rigas A, Papadouri T, Yiallouros PK, et al. Maternal socioeconomic factors and the risk of premature birth and low birth weight in Cyprus: a case-control study. Reprod Health. 2018;15(1):157.

[10] Heiberg IH, Jacobsen BK, Balteskard L, Bramness JG, Naess $\emptyset$, Ystrom E, et al. Undiagnosed cardiovascular disease prior to cardiovascular death in individuals with severe mental illness. Acta Psychiatr Scand. 2019;139(6):558-571. 
Asmita Mahato, and Barsha Shrestha

[11] Goisis A, Remes H, Barclay K, Martikainen P, Myrskylä M. Advanced Maternal Age and the Risk of Low Birth Weight and Preterm Delivery: A Within-Family Analysis Using Finnish Population Registers, Am J Epidemiol. 2017;186(11):1219-1226.

[12] Dhakal P, Shrestha M, Baral D, Pathak S. Factors Affecting the Place of Delivery among Mothers Residing in Jhorahat VDC, Morang, Nepal. Int J Community Based Nurs Midwifery. 2018;6(1):2-11.

[13] Li XL, Du DF, Chen SJ, Zheng SH, Lee AC, Chen Q. Trends in ectopic pregnancy, hydatidiform mole and miscarriage in the largest obstetrics and gynaecology hospital in China from 2003 to 2013. Reprod Health. 2016;13(1):58.

[14] Kozuki N, Lee AC, Silveira MF, Sania A, Vogel JP, Adair L, et al. The associations of parity and maternal age with small-for-gestational-age, preterm, and neonatal and infant mortality: a meta-analysis. BMC Public Health. 2013;13 Suppl 3(Suppl 3):S2.

[15] Sulastri AM, Ni'mah M, Eka N. Contribution to the Number of Pregnancy (Gravida) Complications of Pregnancy and Labor" in Selection and Peer-review under the responsibility of the ICHT Conference Committee. KnE Life Sciences. 2019;316-325. https://doi.org/10.18502/kls.v4i13.5261

[16] Bhide A, Acharya G. Sex differences in fetal heart rate and variability assessed by antenatal computerized cardiotocography. Acta Obstet Gynecol Scand. 2018;97(12):1486-1490.

[17] Kumar S, Kumar R, Tewari A, Richa, Chakraborty SN, Som TK. Prevalence and Determinants of Low Birth Weight: An Experience from a Secondary Referral Unit of Burdwan District, West Bengal (India). IOSR-JDMS. 2018;17(3):54-59.

[18] Bansal P, Garg S, Upadhyay HP. Prevalence of low birth weight babies and its association with socio-cultural and maternal risk factors among the institutional deliveries in Bharatpur, Nepal. Asian J. Med. Sci. 2019;10(1):77-85.

[19] Apte A, Patil R, Lele P, Choudhari B, Bhattacharjee T, Bavdekar A, et al. Demographic surveillance over 12 years helps elicit determinants of low birth weights in India. PLos One. 2019;14(7): e0218587.

[20] Anand P, Gupta R, Sudan JK. Prevalence of low birth weight and associated maternal risk factors among the term neonates during normal deliveries in Jammu, J\& K. Int J Health Sci Res. 2019;9(8):376-383.

[21] Gogoi N. Socio-demographic determinants of low birth weight in Northeastern city, India. Int J Intg Med Sci. 2018;5(3):587- 591.

[22] Kayastha S, Tuladhar H. A Study of LBW babies in Nepal Medical College. Nepal Med College J Dec 2007;10(2):266-9

[23] Taywade ML, Pisudde PM. Study of sociodemographic determinants of low birth weight in Wardha district, India. Clin Epidemiol Glob Heal. 2017;5(1):14-20.

[24] Timilsina S, Karki S, Gautam A, Bhusal P, Paudel G, Sharma D. Correlation between maternal and umbilical cord blood in pregnant women of Pokhara Valley: a cross sectional study. BMC Pregnancy Childbirth. 18, 70(2018). https://doi.org/10.1186/s12884-018-1697-1

[25] de Wilde JA, van Buuren S, Middelkoop BJ. Trends in birth weight and the prevalence of low birth weight and small-for-gestational-age in Surinamese South Asian babies since 1974: cross-sectional study of three birth cohorts. BMC Public Health. 13, 931(2013). https://doi.org/10.1186/1471-2458-13-931

[26] Pildner von Steinburg S, Boulesteix AL, Lederer C, Grunow S, Schiermeier S, Hatzmann W, et al. What is the "normal" fetal heart rate?. PeerJ. 2013;1:e82. Published 2013 Jun 4. https://doi.org/10.7717/peerj.82

[27] Rooth G, Huch A, Huch R. FIGO News: Guidelines for the use of fetal monitoring. Int J Gynaecol Obstet. 1987;25:159-167.

[28] American College of Obstetricians and Gynecologists. ACOG Practice Bulletin No. 106: Intrapartum fetal heart rate monitoring: nomenclature, interpretation, and general management principles. Obstet Gynecol. 2009 Jul; 114(1):192-202.

[29] de Medina PGR, Visser GHA, Huizink AC, Buitelaar JK, Mulder EJH. Fetal behaviour does not differ between boys and girls. Early Hum Dev. 2003;73(1-2):17-26.

[30] McKenna DS, Ventolini G, Neiger R, Downing C. Gender-related differences in fetal heart rate during first trimester. Fetal Diagn Ther. 2006;21(1):144-147.

[31] ÖZGAN ÇELIKEL Ö, AKSOY N. Examination of the relationships between different birthweights and various gestational parameters. J Surg Med. 2018;2(2):55-59. 
[32] Ozdemir O, Tunay ZO, Acar DE, Erol MK, Sener E, Acar U. The relationship of birth weight, gestational age, and postmenstrual age with ocular biometry parameters in premature infants. Arq Bras Oftalmol. 2015; 78: 146149.

[33] Silva WF, Guedes ZCF. Preterm and late preterm infants: their differences and breastfeeding. Rev. Cefac. 2015;17(4):1232-40.

[34] Fuchs F, Monet B, Ducruet T, Chaillet N, Audibert F. Effect of maternal age on the risk of preterm birth: A large cohort study. PLoS one. 2018;13(1):e0191002. https://doi.org/10.1371/journal.pone.0191002

[35] Nazari M, Sharifah Zainiyah SY, Lye MS, Zalilah MS, Heidarzadeh M. Comparison of maternal characteristics in low birth weight and normal birth weight infants. E Mediterr Health J. 2013;19(9):775-781. 